\title{
Role of urotensin II gene in genetic susceptibility to Type 2 diabetes mellitus in Japanese subjects
}

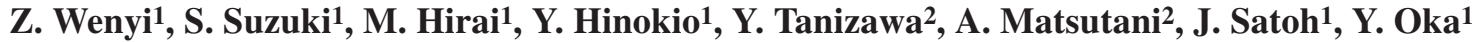 \\ ${ }^{1}$ Division of Molecular Metabolism and Diabetes, Department of Internal Medicine, \\ Tohoku University Graduate School of Medicine, Sendai 980-8574, Japan \\ 2 Division of Molecular Analysis of Human Disorders, Department of Bio-Signal Analysis, \\ Yamaguchi University Graduate School of Medicine, Ube, Japan
}

\section{Abstract}

Aim/Hypothesis. Urotensin II is a potent vasoactive hormone and the urotensin II gene (UTS2) is localized to $1 \mathrm{p} 36-\mathrm{p} 32$, one of the regions reported to show possible linkage with Type 2 diabetes in Japanese subjects. The aim of this study is to investigate a possible contribution of SNPs in the UTS2 gene to the development of Type 2 diabetes.

Methods. We surveyed SNPs in the UTS2 gene in 152 Japanese subjects with Type 2 diabetes mellitus and two control Japanese cohorts: one consisting of 122 elderly subjects who met stringent criteria for being non-diabetic, including being older than 60 years of age with no evidence of diabetes $\left(\mathrm{HbA}_{1 \mathrm{c}}<5.6 \%\right)$, and another 268 subjects with normal glucose tolerance.

Results. We identified two SNPs with amino acid substitutions, designated T21M and S89N. The allele fre- quency of $89 \mathrm{~N}$ was higher in Type 2 diabetic patients than in both elderly normal subjects $(p=0.0018)$ and subjects with normal glucose tolerance $(p=0.0011)$, whereas the allele frequency of $\mathrm{T} 21 \mathrm{M}$ was essentially identical in these three groups. Furthermore, in the subjects with normal glucose tolerance, $89 \mathrm{~N}$ was associated with higher insulin concentrations on oral glucose tolerance test, suggesting reduced insulin sensitivity in subjects with $89 \mathrm{~N}$.

Conclusion/interpretation. These results strongly suggest that the S89N polymorphism in the UTS2 gene is associated with the development of Type 2 diabetes, via insulin sensitivity, in Japanese subjects. [Diabetologia (2003) 46:972-976]

Keywords Urotensin II, single nucleotide polymorphism, insulin resistance, Type 2 diabetes, normal glucose tolerance
Type 2 diabetes is characterized by insulin resistance in insulin target tissues and impaired insulin secretion from pancreatic beta cells [1], both of which are caused by multiple genetic and environmental factors.

Received: 19 November 2002 / Revised: 18 February 2003

Published online: 27 June 2003

C) Springer-Verlag 2003

Corresponding author: Dr. S. Suzuki, Division of Molecular Metabolism and Diabetes, Department of Internal Medicine, Tohoku University Graduate School of Medicine, Sendai 9808574, Japan

E-mail: ssuzuki@int3.med.tohoku.ac.jp

Abbreviations: SNP, Single nucleotide polymorphism; PCRRFLP, polymerase chain reaction-restrict enzyme fragment length polymorphism.
The urotensin II (UTS2) gene is localized to 1p36-p32, one of the regions showing potential linkage with Type 2 diabetes in affected Japanese sib-pairs [2]. Urotensin II is a potent mammalian vasoactive hormone $[3,4,5]$. In human, it constricts both artery and veins in vitro and elicits a reduction in blood flow in the forearm and skin microcirculation in vivo [6]. In addition, urotensin II conducts endothelium-dependent vasodilation [7]. Recent evidence suggests that vascular factor dysfunction contributes to insulin resistance [8]. Urotensin II reportedly reduces glucose-induced insulin secretion in the perfused rat pancreas [9]. Urotensin II could, therefore, contribute to the insulin secretory defects and/or insulin resistance in Type 2 diabetes.

We investigated genetic polymorphisms in the UTS2 gene and showed an association between one 
SNP in the UTS2 gene and the prevalence of Type 2 diabetes in Japanese subjects. Further analysis suggested this SNP to be associated with insulin resistance. We discuss the possible contribution of the UTS2 gene to the pathogenesis of Type 2 diabetes.

\section{Subjects and methods}

Subjects. We randomly recruited 152 unrelated patients with Type 2 diabetes from the outpatient clinic of Tohoku University Hospital. Type 2 diabetes was diagnosed using the World Health Organization (WHO) criteria. For non-diabetic control subjects, we enrolled 122 elderly subjects meeting the following criteria: older than 60 years of age, no past history of diabetes, $\mathrm{HbA}_{1 \mathrm{c}}$ less than $5.6 \%$, and no diabetes in third degree or closer relatives. In addition, a total of 268 subjects with normal glucose tolerance were selected from among people undergoing routine annual health examinations at two hospitals in Japan, Sendai Kosei Hospital and Shimonoseki Kosei Hospital. Normal glucose tolerance was confirmed by a 75 g OGTT using the WHO criteria. The study protocol and genetic analysis of human subjects were reviewed and approved by the Tohoku University Institutional Review Board. Appropriate informed consent was obtained from all subjects examined, including the elderly control subjects and the NGT subjects. The insulin sensitivity index, $\mathrm{HOMA}(\mathrm{R})$, in the NGT subjects were assessed using the HOMA model [10]. The ISI composite [11], another insulin sensitivity index, was calculated from plasma glucose and insulin concentrations during the OGTT. The data needed for these estimations were available in NGT subjects undergoing routine annual health examinations at the Shimonoseki Kosei Hospital $(n=101)$.

Genomic DNA amplification and SNP identification. DNA was isolated from peripheral blood cells using a QIAamp DNA mini kit (QIAGEN, Hilden, Germany). To amplify coding regions and intron-exon boundaries from genomic DNA, a primer set was developed using the genomic sequence for UTS2. A PCR was carried out and each PCR fragment was directly sequenced in both directions (ABI PRISM 7700, PE Applied Biosystems, Mississauga, Ont.,Canada). To screen for variants in UTS2, we sequenced the genomic DNA from 30 unrelated subjects with Type 2 diabetes and that from 30 elderly control subjects.

SNP genotyping by PCR-RFLP. PCR-RFLP (restrict enzyme fragment length polymorphism) was used to examine two SNPs. The nucleotide transition from $\mathrm{C}$ to $\mathrm{T}$ in codon 61 of the UTS2 gene, which results in amino acid transition from Thr to Met at amino acid position 21, generates an Hsp92 II site. This SNP was designated T21M for this study. The PCR fragments amplified with forward primer (5'-ggaaaccaacgtatttcatc- $\left.3^{\prime}\right)$ and reverse primer $\left(5^{\prime}\right.$-gcaaaagaggcaacttacagc- $\left.3^{\prime}\right)$ were digested with Hsp92 II, analysed by electrophoresis in $4 \%$ agarose gel and visualized under UV light. The wild-type DNA (21T) is expected to show two bands with 113 and $28 \mathrm{bp}$, while the mutated DNA (21M) shows three bands with 61,52 , and $28 \mathrm{bp}$. The nucleotide transition from $\mathrm{G}$ to $\mathrm{A}$ in codon 266 (amino acid transition from Ser to Asp at amino acid position 89) eliminates an Afa I site. This SNP was designated S89N. The PCR fragments amplified with forward primer (5'-gtgcctgtctgtctgcattca- $\left.3^{\prime}\right)$ and reverse primer ( $5^{\prime}$-gagtcctgtaaaaccagctacag- $\left.3^{\prime}\right)$ were digested with Afa I and analysed by $4 \%$ agarose gel electrophoresis. The $89 \mathrm{~S}$ is expected to show three bands with 161,84 and 18 bp, while $89 \mathrm{~N}$ shows two bands with 245 and $18 \mathrm{bp}$.

Statistical analysis. The association of SNP genotypes with diabetes was assessed by an analysis of contingency tables. A Fisher's exact test was used to compare differences in proportions between groups. Pair-wise Student's $t$ tests were used to compare differences in the least squares means of quantitative traits between groups. Statistical analyses were done using the statistical analysis package of SPSS. Statistical significance was accepted at the $95 \%$ confidence level $(p<0.05)$.

\section{Results}

We identified two SNPs with amino acid substitutions in the UTS2 gene, designated T21M $(143 \mathrm{~A}>\mathrm{G})$ and $\mathrm{S} 89 \mathrm{~N}$ (in the splice variant a, S74 $\mathrm{N}$ in the splice variant b, 3836T $>$ C), in Japanese control subjects and Type 2 diabetic patients (Fig. 1). We also identified one SNP in the promotor region of the UTS2 gene $(-605 \mathrm{G}>\mathrm{A})$. A case-control study was done by comparing the allele frequencies of UTS2 gene SNPs in 122 elderly control subjects, 268 NGT subjects, and 152 unrelated subjects with Type 2 diabetes. Clinical characteristics of the elderly control subjects, NGT subjects, and Type 2 diabetic patients are summarized in Table 1. The mean age at diabetes onset is 45.8 years in the Type 2 diabetes group. Age at the time of this study was much greater in the elderly control subjects (mean age: 71.6 years) than that of the other con-

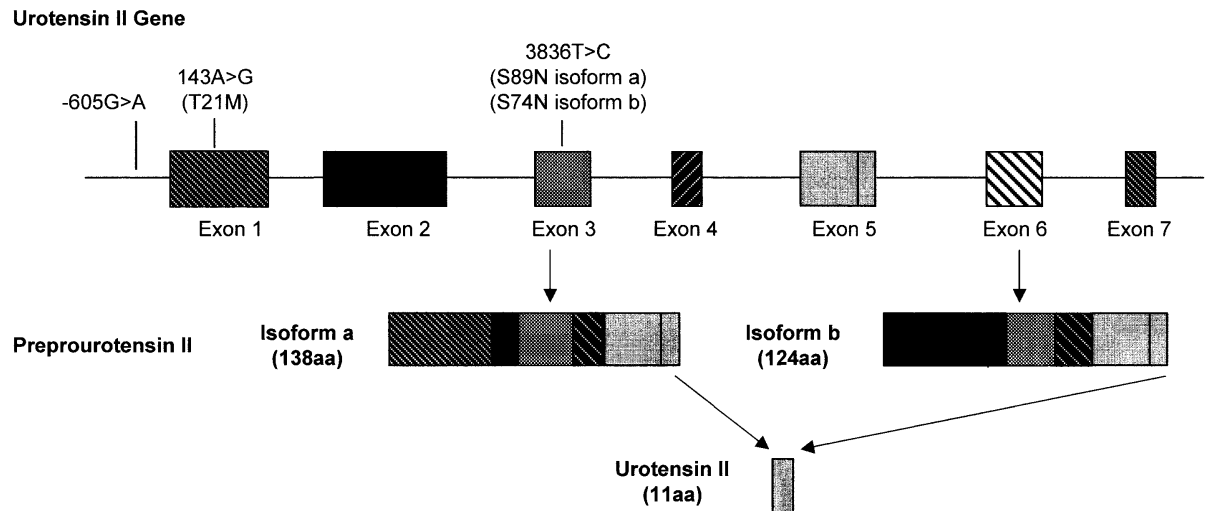

Fig. 1. Genomic structure, splicing variant structure and identified SNPs in the UTS2 gene 
Table 1. Clinical characteristics of elderly control subjects, NGT subjects, and Type 2 diabetic patients

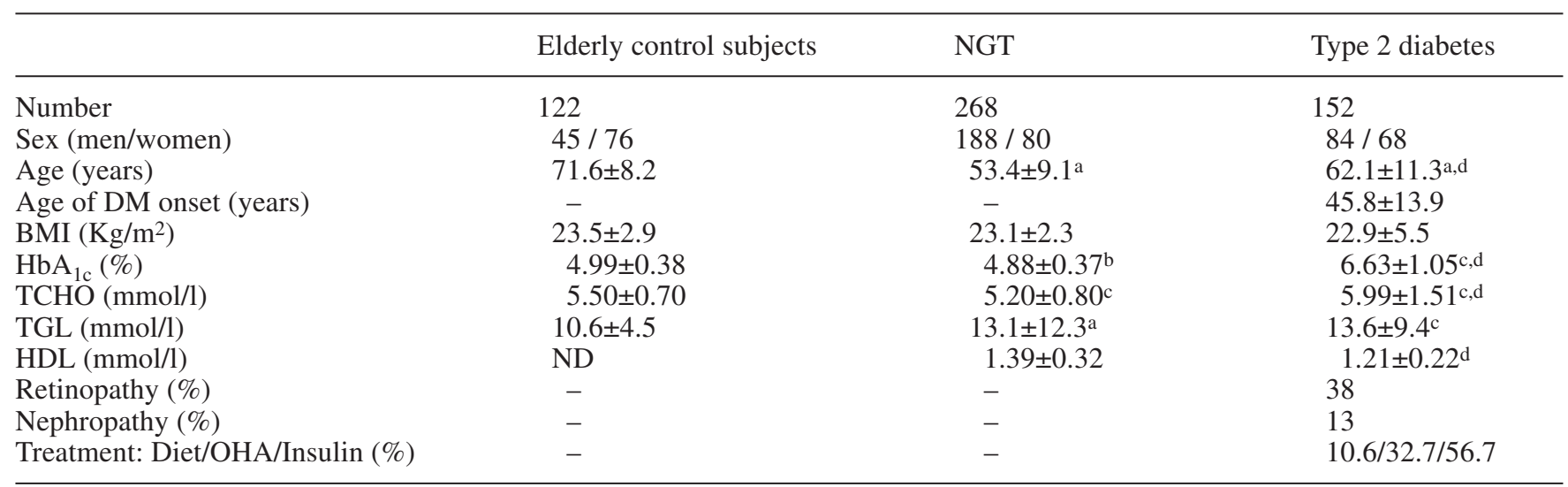

TCHO, total cholesterol; TGL, triglyceride; HDL, HDL-cholesterol; OHA, oral hypoglycemic agent; ND, not determined. Data are expressed as means \pm SD. ${ }^{a} p<0.05$, vs elderly control subjects; ${ }^{\mathrm{b}} p<0.01$, vs elderly control subjects; ${ }^{\mathrm{c}} p<0.001$, vs elderly control subjects; ${ }^{\mathrm{d}} p<0.001$, vs NGT subjects

Table 2. Genotype and allele frequency of S89 N in elderly control subjects, NGT subjects, and Type 2 diabetic patients

\begin{tabular}{lccc}
\hline SNP-89 genotype & Elderly control subjects & NGT subjects & Type 2 diabetes \\
\hline Asn/Asn & $3(2.4 \%)$ & $16(6.0 \%)$ & $11(7.2 \%)$ \\
Ser/Asn & $38(31.2 \%)$ & $74(27.6 \%)$ & $69(45.4 \%)$ \\
Ser/Ser & $81(66.4 \%)$ & $178(66.4 \%)$ & $72(47.4 \%)$ \\
Sum & 122 & 268 & 152 \\
$p$ value & 0.0042 & 0.0005 & Type 2 diabetes \\
SNP-89 allele & Elderly control subjects & NGT subjects & $91(29.9 \%)$ \\
Asn & $44(18.0 \%)$ & $106(19.8 \%)$ & $213(70.1 \%)$ \\
Ser & $200(82.0 \%)$ & $430(80.2 \%)$ & 304 \\
Sum & $244)$ & 536 & \\
$\chi^{2}$ c & 9.70 & 10.6 & 0.0011 \\
Pc value & 0.0018 & 1.73 & \\
Odds ratio & 1.94 & & \\
\hline
\end{tabular}

Data are expressed as means \pm SD (vs Type 2 diabetes)

trol group, NGT subjects (mean age: 53.4 years). The mean age of the Type 2 diabetes group (62.1 years) falls between these two.

The genetic frequency of SNP for Asn at amino acid 89 of preprourotensin II was higher in Type 2 diabetic patients than in the elderly control subjects $(p=0.0042$, Table 2). A highly significant difference in the genotype frequency of SNP-S89N was noted when Type 2 diabetic patients were compared to the other control subjects, the NGT subjects $(p=0.0005)$. These findings were confirmed when allele frequencies were compared. The allele frequency of $89 \mathrm{~N}$ was higher in Type 2 diabetic patients than in the elderly control $(p=0.0018)$ and NGT $(p=0.0011)$ subjects. Although weak linkage disequilibrium was found between SNPS89N and SNP-T21M (D-value: -0.052, D'-value: -0.619), no difference in T21M-SNP was observed; the allele frequency of $21 \mathrm{M}$ was essentially identical in Type 2 diabetic patients (36\%), the elderly control (34\%) and NGT subjects (35\%). The genotype and al- lele frequency of the promotor SNP $(-605 \mathrm{G}>\mathrm{A})$ was also essentially identical in Type 2 diabetic patients, the elderly control and NGT subjects. There was no deviation of observed genotype frequencies from the Hardy-Weinberg expectation in the promotor SNP, the SNP-T21M and the SNP-S89N.

The NGT subjects undergoing routine annual health examinations at Shimonoseki Kosei Hospital had their plasma insulin concentrations measured before and during OGTT. We therefore further studied the possible association of $\mathrm{S} 89 \mathrm{~N}$ with insulin sensitivity and/or insulin secretory capacity in these NGT subjects $(n=101)$. The NGT subjects with the $89 \mathrm{~N}$ allele had increased plasma insulin concentrations at $0 \mathrm{~min}$ and $120 \mathrm{~min}$ and higher plasma glucose concentrations at 120 min of OGTT (Table 3). Their $\sum$ PG, $\sum$ PI (summations of plasma glucose and insulin concentrations during OGTT, respectively) and $\mathrm{HbA}_{1 \mathrm{c}}$ values were also greater than those of subjects with the $89 \mathrm{~S}$ allele. It is noteworthy that the differences are small, as expected 
Table 3. Metabolic parameters in NGT subjects classified according to S89N genotypes or alleles

\begin{tabular}{|c|c|c|c|c|c|c|c|}
\hline & \multicolumn{4}{|l|}{ Genotype } & \multicolumn{3}{|l|}{ Allele } \\
\hline & Asn/Asn & Asn/Ser & Ser/Ser & $p$ value & Asn & Ser & $p$ value \\
\hline Sex (men/women) & $6 / 4$ & $25 / 6$ & $46 / 14$ & NS & $37 / 14$ & $117 / 34$ & NS \\
\hline Age (years) & $52.6 \pm 11.2$ & $54.3 \pm 10.0$ & $53.1 \pm 8.3$ & NS & $53.6 \pm 10.3$ & $53.3 \pm 8.7$ & NS \\
\hline $\mathrm{BMI}\left(\mathrm{Kg} / \mathrm{m}^{2}\right)$ & $23.8 \pm 2.3$ & $23.3 \pm 2.5$ & $22.8 \pm 2.2$ & NS & $23.5 \pm 2.4$ & $22.9 \pm 2.3$ & NS \\
\hline \multicolumn{8}{|c|}{ Plasma glucose (PG mmol/l) } \\
\hline $0 \mathrm{~min}$ & $5.36 \pm 0.55$ & $5.46 \pm 0.37$ & $5.37 \pm 0.39$ & NS & $5.42 \pm 0.44$ & $5.39 \pm 0.38$ & NS \\
\hline $30 \mathrm{~min}$ & $8.81 \pm 1.94$ & $8.32 \pm 1.27$ & $7.88 \pm 1.18$ & NS & $8.52 \pm 1.54$ & $7.97 \pm 1.20$ & NS \\
\hline $60 \mathrm{~min}$ & $8.79 \pm 2.32$ & $8.07 \pm 1.88$ & $7.34 \pm 1.96$ & NS & $8.35 \pm 2.05$ & $7.49 \pm 1.95$ & NS \\
\hline $90 \mathrm{~min}$ & $7.32 \pm 1.38$ & $6.86 \pm 1.74$ & $6.52 \pm 1.47$ & NS & $7.04 \pm 1.60$ & $6.59 \pm 1.52$ & NS \\
\hline $120 \mathrm{~min}$ & $6.57 \pm 0.72$ & $6.21 \pm 0.95$ & $5.91 \pm 0.84$ & NS & $6.35 \pm 0.88$ & $5.97 \pm 0.87$ & 0.0071 \\
\hline $30 \mathrm{~min}$ & $250.8 \pm 112.2$ & $225.0 \pm 133.8$ & $234.0 \pm 151.2$ & NS & $235.2 \pm 124.2$ & $232.2 \pm 147.0$ & NS \\
\hline $60 \mathrm{~min}$ & $390.0 \pm 304.8$ & $262.2 \pm 125.4$ & $251.4 \pm 168.6$ & NS & $312.6 \pm 216.6$ & $253.8 \pm 160.2$ & NS \\
\hline $90 \mathrm{~min}$ & $316.2 \pm 184.8$ & $258.6 \pm 159.6$ & $207.6 \pm 108.6$ & NS & $280.8 \pm 168.6$ & $217.8 \pm 121.8$ & NS \\
\hline $120 \mathrm{~min}$ & $263.4 \pm 125.4$ & $213.0 \pm 125.4$ & $168.6 \pm 90.6$ & 0.0051 & $232.8 \pm 125.4$ & $177.6 \pm 99.6$ & 0.0016 \\
\hline$\sum \mathrm{PG}(\mathrm{mmol} / \mathrm{l})$ & $36.9 \pm 5.8$ & $34.9 \pm 5.3$ & $33.0 \pm 4.4$ & 0.017 & $35.7 \pm 5.4$ & $33.4 \pm 4.6$ & 0.0041 \\
\hline$\sum \mathrm{PI}(\mathrm{pmol} / \mathrm{l})$ & $1272 \pm 641$ & $1003 \pm 442$ & $902 \pm 385$ & 0.014 & $1108 \pm 532$ & $922 \pm 397$ & 0.0089 \\
\hline TCHO (mmol/l) & $5.42 \pm 1.04$ & $5.38 \pm 0.64$ & $5.07 \pm 0.82$ & NS & $5.40 \pm 0.76$ & $5.14 \pm 0.79$ & 0.043 \\
\hline TGL $(\mathrm{mmol} / \mathrm{l})$ & $10.9 \pm 5.3$ & $15.4 \pm 16.2$ & $12.3 \pm 10.6$ & NS & $13.6 \pm 13.1$ & $12.9 \pm 11.9$ & NS \\
\hline $\operatorname{HOMA}(\mathrm{R})$ & $2.04 \pm 0.58$ & $1.78 \pm 0.58$ & $1.62 \pm 0.46$ & 0.0122 & $1.88 \pm 0.58$ & $1.65 \pm 0.49$ & 0.0063 \\
\hline ISI composite & $3.09 \pm 0.67$ & $3.48 \pm 0.82$ & $3.75 \pm 0.70$ & 0.0071 & $3.33 \pm 0.77$ & $3.70 \pm 0.73$ & 0.0023 \\
\hline
\end{tabular}

$\sum$ PG and $\sum$ PI are summaries of plasma glucose and insulin concentrations during OGTT, respectively.

Data are expressed as means \pm SD. (\# Asn/Asn vs Ser/Ser)

in NGT subjects, but statistically significant. Thus, even in NGT subjects, subjects with the $89 \mathrm{~N}$ allele have minimally increased plasma glucose concentrations, accompanied by slightly increased plasma insulin, suggesting that the $89 \mathrm{~N}$ allele contributes to insulin resistance. Indeed, the $\operatorname{HOMA}(\mathrm{R})$ of NGT subjects with the $89 \mathrm{~N}$ allele was higher than that of subjects with the $89 \mathrm{~S}$ allele ( $p=0.0063)$. NGT subjects with the $89 \mathrm{~N}$ allele had lower ISI composite values than NGT subjects with the $89 \mathrm{~S}$ allele $(p=0.0023)$. These data indicate that the $89 \mathrm{~N}$ allele is associated with an insulinresistant phenotype in NGT subjects. In contrast to SNP-S89N, the values described above are essentially identical in subjects with the $21 \mathrm{~T}$ allele and those with the $21 \mathrm{M}$ allele.

\section{Discussion}

We studied two control Japanese cohorts. One comprised elderly subjects who met stringent criteria: 60 or more years of age, no past history of diabetes, $\mathrm{HbA} 1 \mathrm{c}$ less than $5.6 \%$, and no third degree or closer relatives with diabetes. Applying these criteria reduced the possibility of including subjects who would later develop diabetes. The other cohort consisted of subjects undergoing routine annual health examinations and showing NGT on OGTT. Both control groups showed a difference in SNP-S89N frequency as compared to the subjects with Type 2 diabetes. It should be emphasized that the difference is highly statistically significant in this case-control study; $p$ values of allele frequency difference were 0.0018 compared with the elderly control group and 0.0011 compared with the NGT subjects. Involvement of SNPS89N in the development of diabetes was further supported by the results obtained in NGT subjects. Effects of SNP-S89N on glucose metabolism were evident even in NGT subjects. Plasma glucose seems to be slightly increased in NGT subjects with the $89 \mathrm{~N}$ allele as compared to those with the $89 \mathrm{~S}$ allele. Of note, plasma insulin concentrations while fasting (time 0) and at $120 \mathrm{~min}$ of OGTT were also greater in those with the $89 \mathrm{~N}$ allele than in those with the $89 \mathrm{~S}$ allele. $\operatorname{HOMA}(\mathrm{R})$, which is calculated from fasting plasma glucose and insulin concentrations, is greater in those with the $89 \mathrm{~N}$ allele. These results strongly suggest that subjects with the $89 \mathrm{~N}$ allele are more insulin-resistant than those with the $89 \mathrm{~S}$ allele, and are thus more likely to develop diabetes.

Urotensin II is a potent vasoconstrictor in human arteries and veins $[3,4,5]$, exerting its biological ef- 
fects via interaction with a member of a G-proteincoupled receptor superfamily, originally termed GPR14 $[12,13,14]$. Insulin induces endothelial-nitric oxidedependent vasodilatation. Recent data suggest that insulin's metabolic and vascular actions are closely linked [8]. Insulin-resistant states are associated with diminished insulin-mediated glucose uptake into peripheral tissues, and impaired insulin-mediated vasodilatation as well as impaired endothelium-dependent vasodilatation in response to the muscarinic receptor agonist acetylcholine. Several vasoactive hormones including endothelin-1, modulate insulin-mediated vasodilatation induce insulin resistance in peripheral tissues and endothelium [8]. Urotensin II also conducts endothelium-dependent vasodilation [5, 6], however there have been no data showing whether it modulates insulin-mediated vasodilatation and insulin sensitivity in vivo. Our study suggests that SNP of the gene for urotensin II contributes to insulin resistance.

Urotensin II is a cyclic dodecapeptide, derived from two splice variants of preproprotein with 124 or 138 amino-acids through proteolytic cleavage by putative polybasic endopeptidase, as shown in Fig. 1 [3, $15,16]$. There are no previous reports indicating that the amino acid transition from Ser to Asn at position 89 influences the post-translational processing of preprourotensin II. Future investigation should focus on whether $\mathrm{S} 89 \mathrm{~N}$ affects the processing and/or secretion of urotensin II. The possible involvement of UTS2 SNP-S89N in Type 2 diabetes as well as insulin resistance merits study in ethnic groups other than Japanese subjects.

In conclusion, our results strongly suggest that subjects with $\mathrm{S} 89 \mathrm{~N}$ in the UTS2 gene are more insulin resistant and thus more susceptible to developing Type 2 diabetes mellitus. The UTS 2 gene is among the diabetogenic genes in the Japanese population.

Acknowledgements. We are grateful to all of the patients who participated in this study and to their referring physicians. We would also like to thank the elderly control and NGT subjects for participating. This study was supported by Grants in Aid for Creative Basic Research (10NP0210) and for Scientific Research (13204062) to Y. Oka and Grants in Aid for Scientific Research (70216399) to S. Suzuki from the Ministry of Education, Science, Sports and Culture of Japan. We gratefully acknowledge the expert assistance of Chitose Suzuki.

\section{References}

1. DeFranzo RA, Bonadonna RC, Ferrannini E (1992) Pathogenesis of NIDDM: a balanced overview. Diabetes Care 15: 318-368

2. Mori Y, Otabe S, Dina C et al. (2002) Genome-wide search for type 2 diabetes in Japanese affected sib-pairs confirms susceptibility genes on $3 \mathrm{q}, 15 \mathrm{q}$, and $20 \mathrm{q}$ and identifies two new candidate loci on 7p and 11p. Diabetes 51:1247-1255

3. Ames RS, Sarau HM, Chambers JK et al. (1999) Human urotensin-II is a potent vasoconstrictor and agonist for the orphan receptor GPR14. Nature 401:282-286

4. Douglas SA, Ohlstein EH (2000) Human urotensin-II, the most potent mammalian vasoconstrictor identified to date, as a therapeutic target for the management of cardiovascular disease. Trends Cardiovasc Med 10:229-237

5. Bohm F, Pernow J (2002) Urotensin II evokes potent vasoconstriction in humans in vivo. Br J Pharmacol 135:25-27

6. Maguire JJ, Davenport AP (2002) Is urotensin II the new endothelin? Br J Pharmacol 137:579-588

7. Bottrill FE, Douglas SA, Hiley CR, White R (2000) Human urotensin-II is an endothelium-dependent vasodilator in rat small arteries. Br J Pharmacol 130:1865-1870

8. Baron AD (2002) Insulin resistance and vascular function. J Diabetes Complications 16:92-102

9. Silvestre RA, Rodriguez-Gallardo J, Egido EM, Marco J (2001) Inhibition of insulin release by urotensin II-a study on the perfused rat pancreas. Horm Metab Res 33:379-381

10. Matthews DR, Hosker JP, Rudenski AS, Naylor BA, Treacher DF, Turner RC (1985) Homeostasis model assessment: insulin resistance and beta-cell function from fasting plasma glucose and insulin concentrations in man. Diabetologia 28:412-419

11. Matsuda M, DeFronzo RA (1999) Insulin sensitivity indices obtained from oral glucose tolerance testing: comparison with the euglycemic insulin clamp. Diabetes Care 22:1462-1470

12. Liu Q, Pong SS, Zeng Z et al. (1999) Identification of urotensin II as the endogenous ligand for the orphan G-protein-coupled receptor GPR14. Biochem Biophys Res Commun 266:174-178

13. Mori M, Sugo T, Abe M et al. (1999) Urotensin II is the endogenous ligand of a G-protein-coupled orphan receptor, SENR (GPR14). Biochem Biophys Res Commun 265: 123-129

14. Nothacker HP, Wang Z, McNeill AM et al. (1999) Identification of the natural ligand of an orphan G-protein-coupled receptor involved in the regulation of vasoconstriction. Nat Cell Biol 1:383-385

15. Coulouarn Y, Lihrmann I, Jegou S et al. (1998) Cloning of the cDNA encoding the urotensin II precursor in frog and human reveals intense expression of the urotensin II gene in motoneurons of the spinal cord. Proc Natl Acad Sci USA 95:15803-15808

16. Elshourbagy NA, Douglas SA, Shabon US (2002) Molecular and pharmacological characterization of genes encoding urotensin-II peptides and their cognate G-protein-coupled receptors from the mouse and monkey. $\mathrm{Br} \mathrm{J}$ Pharmacol $136: 9-22$ 